\title{
PBL session conducted for second year undergraduate students of medicine and dentistry at Universal College of Medical Sciences Nepal: Perception of the participants
}

\author{
PiryaniRano Mal $^{1}$, Piryani Suneel ${ }^{2}$, Gautam Narayan ${ }^{3}$
}

1Professor\& HOD Internal Medicine, and Chief Coordinator-Health Professions Training Committee, Universal College of Medical Sciences, Bhairahawa, Nepal

${ }^{2}$ Research Specialist, Department of Community Health Sciences, Aga Khan University Karachi, Pakistan

${ }^{3}$ Associate Professor, Department of Biochemistry, Coordinator PBL Implementation Committee, Universal College of Medical Sciences, Bhairahawa, Nepal

\begin{abstract}
Background and Objectives: Problem-based-learning (PBL) is generallyrecognized as a student centered instructional approach. Universal College of Medical Sciences Nepal introduced PBL to second year MBBS and BDSstudents in July 2019.This study assessed the perceptions of students of second year MBBS and BDS who participated in PBL session.

Material and Methods: This was a cross-sectional questionnaire-based study assessing perceptions of the participant students. The validated questionnaire was used for the collection of data at the end of PBL session. The questionnaire comprised of two parts; Part I- Students'perceptions and attitude towards PBL (9 statements) and Part II Students' perceptions about the role of tutor in PBL(11 statements).Data were analyzed using SPSS version 21. The frequency, mean and standard deviation were computed and t test was used for the comparison of responses on statements of MBBS and BDS groups.

Results: The mean scores on7 out of 9 statements onstudents'perceptions and attitude towards PBLwas higher than fourat Likert scale 1-5 (5=strongly agree, 4=agree, 3=to some extent agree, 2=disagree, $1=$ strongly disagree) and on 2 statements was higher than 3.5. The mean scores on all the statements with regard to students' perception about the role of tutor in PBLwere higher than four. The mean scores of both MBBS and BDS groups of students on all statements were compared; the significant differences were obtained only on 2 statements out of 20 .
\end{abstract}

Conclusion: The perceptionsand attitude of studentstowards PBL and perceptions about the role of tutor were positive.

Keywords: Attitude, BDS, MBBS,PBL, Perceptions, Students

\section{INTRODUCTION}

The problem-based-learning (PBL) was first incorporated in medical curriculumby McMaster University, Canada in 1960s. Subsequently, it has been adopted as a method of teaching learning by various medical and dental schools in the world. PBL as an instructional strategy uses carefully constructed clinical problems in a context for students to define their learning needs, conduct 
self-directed enquiry, integrate theory and practice, and apply knowledge and skills to develop a solution for a defined problem [1-5].

PBL has been a basic component of most of the medical and dental curricula globally. It was first introduced in Nepal in Integrated Basic Medical Sciences Curriculum of Tribhuvan University (TU)Institute of Medicinein 1980s, later on discontinued. BP Koirala Institute of Health Sciences introduced PBL in 1998, followed by Kathmandu University School of Medical Sciences and its affiliated colleges in 2011, and Patan Academy of Heath Sciences in 2011 [1-4].

In TU-affiliated medical colleges, PBL was first experimented at KIST Medical College Lalitpur [3, 5] then inChitwan Medical College Bharatpur in academic year 2014-2015 [1]. Universal College of Medical Sciences (UCMS) Bhairahawa Nepal is third TU-affiliated medical college administered PBL first in June 2019.

PBL implementation committee of UCMS conducted one PBL sessionfor the students of second year MBBS and BDS in July 2019.This study was done to obtain feedback from the participant students of second year MBBS and BDS and explore their perceptions regarding learning in PBL and obtained their views about the role of tutor.

\section{MATERIALS AND METHODS}

Universal College of Medical Sciences (UCMS) Bhairahawa, Nepal conducts undergraduate and postgraduate courses in medicine, dentistry, nursing and allied sciences [6]. It followsthe MBBS curriculum (revised in 2008) and BDS curriculum (1999) of Tribhuvan University Institute of Medicine (TU-IOM) as it is affiliated with TU-IOM [1, 7-8]. The curriculum is systemic, horizontally integrated, community oriented, and more towards teacher centered. After successful implementation of PBL session for students of first year MBBS and BDS in June 16- 21, 2019, PBL implementation committee of Health Professions Training Committee (HPTC) of UCMS developed plan for the implementation of one PBL session for students of second year MBBS and BDS. The session was conducted in fourth week of July 22- 28, 2019.

Total number of studentsenrolled in 2nd year MBBS/BDS was 150 (MBBS 100 and BDS 50). They were divided into 10 groups randomly. Students were informed one week ahead about the schedule of PBL session and grouping. Each group was comprised of 15 students, 10 from MBBS and 5 from BDS. Places for 10 tutorial rooms with adequate number of seats and teaching learning aids (Logistics like flip board, white board etc. and stationary like flip chart papers, markers etc.) were arranged. Out of 150 , 143 participated in PBL session (MBBS 98, BDS 45).

Students were oriented on first day in one-hour interactive session covering what is $\mathrm{PBL}$, why PBL, what is process of PBL, what is scenario, what is trigger, what are cues, learning needs, and learning objectives, what is role of tutor, how students have to participate in tutorial, what is self-directed learning (SDL), what are learning resources, how learning resources can be used, about small group work discussion etc. Tutorials were arranged for two hours 11.00-13.00 for first five days Monday to Friday in July 22- 26, 2019 with supervised SDL for 2 hours daily in the afternoon 14.00-16.00 hours with SDL continued at hostel. The seminar was held on Sunday i.e. July 28, 2019. The tutorial evaluation was done by tutor for the communication skills, about knowledge, problem solving and analytical thinking skills and personal and interpersonal development and the results were shared with students after seminar. 
Students consented to provide feedback on PBL session. The feedback from the students was taken on already validated structured questionnaires downloaded from two articles from google $[1,9]$. The feedback questionnaire was comprised of two parts; Part IStudents'perceptions and attitude towards PBL (9 statements) [1] and Part II Students' perceptions about the role of tutor in PBL (11 statements) [9].Ethical approval of the study was taken from ethical review committee of UCMS.

The data collected was checked for completeness, accuracy and consistency. It was entered in IBM SPSS version 21 for analysis. Descriptive analysis was done; the frequency, mean and standard deviation were computed and t test was used for the comparison of responses on statements of MBBS and BDS groups of students

\section{RESULTS}

The mean age of the 2nd year MBBS/BDS students were 20.66 \pm 1.35 years (range 18-27 years); $88(61.5 \%)$ students were males and $55(38.5 \%)$ females. Ninety-eight $(68.5 \%)$ were from MBBS program and 45 (31.5\%) from BDS. The mean age of MBBS students was $20.85 \pm 1.29$, while BDS $20.27 \pm 0.92$ (p-0.021).

The findings regarding students' perceptions and attitude towards PBL as well as students' perception about the role of tutor in PBLare shown in tables 1-4.

\section{DISCUSSION}

The present study revealed the perceptions of 2nd year MBBS and BDS (Basic Sciences) students who participated in PBL session conducted at Universal College of Medical Sciences, Bhairahawa, Nepal in July 2019. Students' constructive perceptions and confidenceabout learning in PBL session after participation is critical for the success of implementation of PBL, and considered as an evidence of acceptance of PBL by the students. PBL has equally a better learning outcome in basic sciences medical education mentioned by Niwa $M$ et al in their study [10].

The present study revealed positive perceptions and attitude of students towards PBL at Likert scale 1-5 (5=strongly agree, $4=$ agree, $3=$ to some extent agree, 2 =disagree. 1=strongly disagree); I found the PBL course interesting (4.48 \pm 0.58 ), I found the course focusing on common medical problems and seemed to be relevant to my interests (4.40 \pm 0.58 ), I agree working in groups means learning from one another (4.52 \pm 0.59$)$, I understood the applied aspects of the course better than if it had been lectured in the conventional way (4.29 \pm 0.82$)$, This approach took less time compared to conventional lecture in learning the course as per objectives $(3.5 \pm 0.95)$, The discussion in the tutorial group determines to a large extent what I will study (4.18 \pm 0.77$)$, The tutorial group discussion was an important stimulus for my learning activities during self-study (4.42 \pm 0.69 ), The learning issues generated were the most important starting point for my learning activities during self-study $(4.25+0.68)$, I studied to a large extent independently from the learning issues generated $(3.92+0.80)$.

Various studies conducted in the past documented positive perceptions and attitude of students towards PBL.Majority of the students liked PBL and they cited group discussion in tutorial was stimulus for leaning and determined what they wish to learn mentioned in the study done by Yadav R M et al. [1]. Bhattacharya $\mathrm{N}$ et al in their study revealed that students expressed enthusiasm to participate in PBL session, majority of the students found PBL more thoughtprovoking than traditionallecture, most of the students found tutorial useful and students felt 
Table 1: Students' Perceptions and Attitude towards PBL: Mean Score in Likert scale

\begin{tabular}{|l|l|}
\hline \multicolumn{1}{|c|}{ Statement } & Mean Score \pm SD \\
\hline 1. I found the PBL course interesting. & $4.48 \pm 0.58$ \\
\hline $\begin{array}{l}\text { 2. I found the course focusing on common medical problems and seemed to be relevant to my } \\
\text { interests. }\end{array}$ & $4.40 \pm 0.58$ \\
\hline 3. I agree working in groups means learning from one another. & $4.52 \pm 0.59$ \\
\hline $\begin{array}{l}\text { 4. I understood the applied aspects of the course better than if it had been lectured in the } \\
\text { conventional way. }\end{array}$ & $4.29 \pm 0.82$ \\
\hline $\begin{array}{l}\text { 5. This approach took less time compared to conventional lecture in learning the course as per } \\
\text { objectives. }\end{array}$ & $3.49 \pm 0.95$ \\
\hline $\begin{array}{l}\text { 6. The discussion in the tutorial group determines to a large extent what I will study. } \\
\text { 7. The tutorial group discussion was an important stimulus for my learning activities during self- } \\
\text { study. }\end{array}$ & $4.18 \pm 0.77$ \\
\hline $\begin{array}{l}\text { 8. The learning issues generated were the most important starting point for my learning activities } \\
\text { during self-study. }\end{array}$ & $4.42 \pm 0.69$ \\
\hline $\begin{array}{l}\text { 9. I studied to a large extent independently from the learning issues generated } \\
\text { SD, Standard deviation; Likert scale Score 1-5 (5=strongly agree, 4=agree, 3=to some extent agree, 2=disagree. 1=strongly disagree }\end{array}$ & $3.92+0.80$ \\
\hline
\end{tabular}

Table 2: Students' perceptions about the role of tutor in PBL: Mean Score in Likert scale

\begin{tabular}{|l|l|}
\hline \multicolumn{1}{|c|}{ Statement } & Mean \pm SD \\
\hline 10. The tutor stimulated us to summarize what we had learnt in our own words & $4.26 \pm 0.73$ \\
\hline 11. The tutor stimulated us to search for links between issues discussed in the tutorial group & $4.46 \pm 0.59$ \\
\hline 12. The tutor stimulated us to understand underlying mechanisms/theories. & $4.26 \pm 0.71$ \\
\hline 13. The tutor stimulated us to generate clear learning issues by ourselves & $4.40 \pm 0.70$ \\
\hline 14. The tutor stimulated us to search for various resources by ourselves & $4.43 \pm 0.60$ \\
\hline 15. The tutor stimulated us to apply knowledge to the discussed problem & $4.45 \pm 0.65$ \\
\hline 16. The tutor stimulated us to apply knowledge to other situations/problems. & $4.31 \pm 0.71$ \\
\hline 17. The tutor stimulated us to give constructive feedback about our group work & $4.36 \pm 0.73$ \\
\hline 18. The tutor stimulated us to evaluate group co-operation regularly & $4.48 \pm 0.64$ \\
\hline 19. The tutor had a clear picture about his/her strengths/weaknesses as a tutor & $4.15 \pm 0.75$ \\
\hline 20. The tutor was clearly motivated to fulfill their role as a tutor & $4.57 \pm 0.54$ \\
\hline
\end{tabular}

SD, Standard deviation; Likert scale 1-5 (5=strongly agree, 4=agree, 3=to some extent agree, 2=disagree. 1=strongly disagree)

Table 3: Comparison between Mean Likert Scale Score of $2^{\text {nd }}$ Year MBBS and BDS students group on Students' Perceptions and Attitude towards PBL

\begin{tabular}{|c|c|c|c|}
\hline Statement & MBBS & BDS & p-value \\
\hline 1. I found the PBL course interesting. & $4.48 \pm 0.60$ & $4.47 \pm 0.55$ & 0.899 \\
\hline $\begin{array}{l}\text { 2. I found the course focusing on common medical problems and seemed to } \\
\text { be relevant to my interests. }\end{array}$ & $4.43 \pm 0.59$ & $4.33 \pm 0.56$ & 0.359 \\
\hline 3. I agree working in groups means learning from one another. & $4.43 \pm 0.63$ & $4.73 \pm 0.45$ & 0.001* \\
\hline $\begin{array}{l}\text { 4. I understood the applied aspects of the course better than if it had been } \\
\text { lectured in the conventional way. }\end{array}$ & $4.31 \pm 0.85$ & $4.24 \pm 0.74$ & 0.662 \\
\hline $\begin{array}{l}\text { 5. This approach took less time compared to conventional lecture in learning } \\
\text { the course as per objectives. }\end{array}$ & $3.50 \pm 0.98$ & $3.47 \pm 0.89$ & 0.841 \\
\hline $\begin{array}{l}\text { 6. The discussion in the tutorial group determines to a large extent what I } \\
\text { will study. }\end{array}$ & $4.17 \pm 0.75$ & $4.20 \pm 0.84$ & 0.857 \\
\hline $\begin{array}{l}\text { 7. The tutorial group discussion was an important stimulus for my learning } \\
\text { activities during self-study. }\end{array}$ & $4.40 \pm 0.71$ & $4.47 \pm 0.62$ & 0.561 \\
\hline $\begin{array}{l}\text { 8. The learning issues generated were the most important starting point for } \\
\text { my learning activities during self-study. }\end{array}$ & $4.21 \pm 0.72$ & $4.33 \pm 0.56$ & 0.287 \\
\hline $\begin{array}{l}\text { 9. I studied to a large extent independently from the learning issues } \\
\text { generated }\end{array}$ & $3.90 \pm 0.84$ & $3.98 \pm 0.69$ & 0.552 \\
\hline
\end{tabular}

\footnotetext{
*, significant; Likert scale 1-5 (5=strongly agree, 4=agree, 3=to some extent agree, 2=disagree. 1=strongly disagree
}

more confident in their capacity to learn on their own [11]. The design of PBL session enables leaners to achieve their learning objectives, revealed by Khan $\mathrm{N}$ et al in their study [12] Anita 
Janaki Medical College Journal of Medical Sciences (2021); Vol.9 (1):55-60

Table 4: Comparison between Mean Likert Scale Score of $2^{\text {nd }}$ Year MBBS and BDS students group onStudents' perceptions about the role of tutor in PBL

\begin{tabular}{|c|c|c|c|}
\hline Statement & MBBS & BDS & p-value \\
\hline 10. The tutor stimulated us to summarize what we had leant in our own words & $4.30 \pm 0.56$ & $4.22 \pm 0.52$ & 0.443 \\
\hline $\begin{array}{l}\text { 11. The tutor stimulated us to search for links between issues discussed in the } \\
\text { tutorial group }\end{array}$ & $4.49 \pm 0.60$ & $4.40 \pm 0.58$ & 0.396 \\
\hline 12. The tutor stimulated us to understand underlying mechanisms/theories. & $4.23 \pm 0.73$ & $4.31 \pm 0.67$ & 0.539 \\
\hline 13. The tutor stimulated us to generate clear learning issues by ourselves & $4.32 \pm 0.75$ & $4.58 \pm 0.50$ & 0.016* \\
\hline 14. The tutor stimulated us to search for various resources by ourselves & $4.42 \pm 0.59$ & $4.47 \pm 0.59$ & 0.664 \\
\hline 15. The tutor stimulated us to apply knowledge to the discussed problem & $4.45 \pm 0.67$ & $4.47 \pm 0.59$ & 0.874 \\
\hline 16. The tutor stimulated us to apply knowledge to other situations/problems. & $4.36 \pm 0.70$ & $4.22 \pm 0.70$ & 0.291 \\
\hline 17. The tutor stimulated us to give constructive feedback about our group work & $4.34 \pm 0.73$ & $4.42 \pm 0.72$ & 0.515 \\
\hline 18. The tutor stimulated us to evaluate group co-operation regularly & $4.47 \pm 0.64$ & $4.51 \pm 0.63$ & 0.715 \\
\hline 19. The tutor had a clear picture about his/her strengths/weaknesses as a tutor & $4.16 \pm 0.77$ & $4.13 \pm 0.73$ & 0.823 \\
\hline 20. The tutor was clearly motivated to fulfill their role as a tutor & $4.53 \pm 0.56$ & $4.64 \pm 0.48$ & 0.217 \\
\hline
\end{tabular}

*, significant; Likert scale 1-5 (5=strongly agree, 4=agree, $3=$ =to some extent agree, 2 =disagree. 1=strongly disagree

Devi $\mathrm{K}$ et el documented that students preferred the PBL mode of learning and felt that this mode of teaching boost their interest in learning the relevant subjects [13]. Al-Drees et al reported that students revealed PBL session encourages collaborative learning and a positive role of the PBL sessions in the students' learning process [14].

The present study found positive perceptions of the students regarding role of tutor in PBL at Likert scale 1-5 (5=strongly agree, $4=$ agree, $3=$ to some extent agree, 2=disagree. 1=strongly disagree); The tutor stimulated us to summarize what we had learnt in our own words (4.26 \pm 0.73$)$, The tutor stimulated us to search for links between issues discussed in the tutorial group (4.46 \pm 0.59$)$, The tutor stimulated us to understand underlying mechanisms/ theories (4.26 \pm 0.71$)$, The tutor stimulated us to generate clear learning issues by ourselves $(4.40 \pm 0.70)$, 17. The tutor stimulated us to search for various resources by ourselves $(4.43 \pm 0.60)$, The tutor stimulated us to apply knowledge to the discussed problem (4.45 \pm 0.65$)$, The tutor stimulated us to apply knowledge to other situations /problems (4.31 \pm 0.71$)$, The tutor stimulated us to give constructive feedback about our group work $4.36 \pm 0.73$, The tutor stimulated us to evaluate group co-operation regularly (4.48 \pm 0.64$)$, The tutor had a clear picture about his/her strengths/weaknesses as a tutor (4.15 \pm 0.75$)$, and The tutor was clearly motivated to fulfill their role as a tutor $(4.57 \pm 0.54)$.

Different studies done in the past reported positive perceptions of the students regarding role of tutor in PBL. Yadav et al reported that student felt tutors were acting like facilitator during group discussion; played very critical roles in maintaining the group dynamics; facilitated them in finding the learning issues and acted as guide; stimulated students for selfdirected learning to explore for links between hypothesis generated in discussion and to appreciate underlying mechanisms and theories [1]. The students felt that the intervention of facilitator was adequate mentioned in the study conducted by Anita Devi K et al. [13]. Othman SY et al documented in their study the key role of tutor is to facilitate PBL process by keeping the group focused on objectives/tasks and guiding the students to achieve their goals [15].

The mean scores of both MBBS and BDS groups of students on all statements were compared; the statistically significant differences were obtained only on 2 statements I agree working in groups 
means learning from one another (MBBS $4.43 \pm 0.72$, BDS $3.73 \pm 0.45$, p- 0.001) and the tutor stimulated us to generate clear learning issues by ourselves (MBBS 4.32 \pm 0.75 , BDS $4.58 \pm 0.50$, p- 0.016) and also in age (MBBS $20.85 \pm 1.29$, BDS $20.27 \pm 0.92$ p-0.021) but in both the groups score on other statements was around 4. In one statement (I agree working in groups means learning from one another) it was higher in MBBS group while in other statement (the tutor stimulated us to generate clear learning issues by ourselves) it was higher in BDS group. Practically it is difficult to explain.

\section{CONCLUSION}

This study reflected a positive perceptions and attitude of students towards PBLand also positive perceptions of the students regarding role of tutor in PBL.

\section{ACKNOWLEDGEMENT}

Authors acknowledge the support of Management of UCMS, Bhairawa, Nepal for permitting to carry out this research and appreciate students for their participation in study

\section{REFERENCES}

1. Yadav RM, Piryani RM, Deo GP, Sah DK, Yadav LK, Islam MN. Attitude and perception of undergraduate medical students towards problem-based learning in Chitwan Medical College. Advance in medical Education and Practice 2018:9 317-322

2. Vogt K, Pelz J, Stroux A. Refinement of a training concept for tutors in problem-based learning. GMS Journal for Medical Education 2017; 34(4), ISSN 2366-5017

3. Sathya Pl, Reddemma K. Development of problem-based learning training module in nursing education.Int J Res Med Sci. 2017 May;5(5):1986-1990

4. Pradhan B, Ranjit E, Ghimire MR, Dixit H. History of problem-based learning in Nepal and experiences at Kathmandu Medical College. J Kathmandu Med Coll. 2012;1(1):37-44.

5. Yew EH, Schmidt HG. Evidence for constructive, selfregulatory, and collaborative processes in problem- based learning. Adv Health SciEduc Theory Pract. 2009;14(2):251-273.

6. Overview UCMS. www.ucms.com.np

7. Curriculum for Bachelor of Medicine \& Bachelor of Surgery Tribhuvan University Institute of Medicine. Revised in 2008 published by Medical Education Department, Institute of Medicine, Kathmandu, Nepal

8. Curriculum for Bachelor of Dentistry Tribhuvan University Institute of Medicine. Revised in 199 published by Medical Education Department, Institute of Medicine, Kathmandu, Nepal

9. Boelens R, De Wever B, Rosseel Y, Verstraete AG, DereseA.What are the most important tasks of tutors during the tutorials in hybrid problem-based learning curricula?BMC Medical Education 2015; 15:84 DOI 10.1186/s12909-015-0368-4

10. Niwa M, Saiki T, Fujisaki K, Suzuki Y, Evans P. The effects of Problem-Based learning on the Academic Achievements of Medical Students, Over a Twenty-Year Period. Health Professions Education 2016; 2: 3-9. http://dx.doi.org/10.1016/j.hpe.2016.01.003

11. Bhattacharya N, Shankar N Khaliq F, Rajesh C S, Tandon OP. Introducing problem-based learning in the conventional Indian Medical Curriculum. Natl Med J India $2005 ; 18: 92-95$

12. Khan N, Ghani N, Suliman M, Khan A, Saadullah B. Perception of Nursing Students about Problem-Based Learning (PBL) in Nursing Institutions of Peshawar, KPK, Pakistan. International Journal of Innovative Research \& Development 2015; 4 (1): 278-284

13. Anita Devi K, Pathak R, Chai JW, Noor H, Rohaini M, et al. Early Introduction of Problem - Based Learning into the Integrated Curriculum of a Newly Established Medical School in Malaysia. J Community Med Health Educ 2012; 2:189. doi:10.4172/2161-0711.1000189

14. Al-Drees A A, Khalil M S, Irshad M, Abdulghani HM. Students perception towards the problem-based learning tutorial session in a system-base hybrid curriculum. Saudi med J 2015; 36 (3): 341- 348

15. Othman SY, Shalaby SA. Students' perception and acceptance of problem-based learning approach in critical care nursing practice. Presented at: Scientific Cooperation International Workshops on Medical Topics; June 7-8; 2014; Ankara, Turkey.

\section{Corresponding Author:}

Dr. PiryaniRano Mal

Professor \& HOD, Department of Internal Medicine Chief Coordinator- Health Professions Training Committee Universal College of Medical Sciences, Bhairahawa, Nepal

E mail: rano.piryani@gmail.com, r piryani@hotmail.com 